\section{WRITTEN EXPRESSION IN SCIENCE}

\begin{abstract}
A CONFERENCE at the City Boys' School, Leicester, convened and presided over by the headmaster, Mr. R. W. Crammer, was held on March 12 to discuss the problem of the difficulty experienced by science graduates in writing reports and the ways in which the grammar schools could help in overcoming it. Dr. U. R. Evans, reader in the science of metallic corrosion in the University of Cambridge, who had raised the matter in the University Senate House, addressed the conference in a private capacity. There were seventy people present, including the heads of grammar schools in the City and County of Leicester, their English and science masters and mistresses and representatives from Leicester University College, the Domestic Science College and the Women's Training College. The conference was welcomed not only because of the importance of its subject but also because it brought together representatives of the grammar schools and of institutions of higher education for the discussion of a common concern.
\end{abstract}

In his address, Dr. Evans said that one of the few serious complaints raised to-day against the young scientific graduate refers to his alleged inability to express findings in a written report. Since a report still represents the best means available for a scientific worker to share his knowledge with others, the complaint is a serious one, and suggests that the writing of English does not receive sufficient attention at schools and universities. The dreary character of many papers printed to-day in scientific journals provides further evidence. Complaints are heard of the excessive length of papers submitted for publication, and it is often felt that the mode of presentation is such that a paper fails to hold the attention of those whom it ought to interest; a common fault is the omission to make clear the reasons for selecting the subject of investigation, and to emphasize the significance of the results for those working on other subjects.

The main trouble seems to arise from the fact that often the young scientific worker has no love for writing. Whatever disciplinarians may say, it is doubtful whether anyone makes a real success of a task which gives him no sort of satisfaction. Enthusiastic and hard-working experimenters show an obvious reluctance to produce reports by the appointed day, and require a surprising length of time to produce a very simple memorandum. Even if the results, when ultimately completed, were perfect, the obvious disinclination to use the pen in the communication of ideas reveals an unsatisfactory state of affairs. This aversion to writing is often shown by men who are extremely successful in explaining their ideas by word of mouth.

It is significant that the difficulties affect many who have attained conspicuous success in the examination hall; there they may have been helped, in a manner of which they were scarcely aware, by the fact that they were writing down facts or arguments previously read in a book or heard at a lecture. When suddenly confronted with the task of discovering for themselves a sequence of words to express something hitherto unreduced to verbal form, they experience the same difficulty as is met with by someone who, at the age of twenty, starts to express himself in French or German. In both cases the difficulty would probably be lessened if the first attempts were made at an earlier age.

There are certain grammatical problems met with in reports which, unless solved, can endanger correct understanding. A report usually refers to work accomplished within some definite period, and starts with a statement of the position at the outset, largely based on the work of the previous period; here the correct employment of pluperfects and perfects often presents difficulty. Next will come the programme for the new period, and now the periphrastic constructions needed to express plans made in the relatively distant past for work in the immediate past sometimes involve perplexityespecially since subjunctives and conditionals must often be introduced (for example, where there has been doubt as to how the plans would work out). In the experimental section the problems of expression are mainly technical, but the author's interpretation of his results, involving comparisons with the views of others, may necessitate passage between oratio recta and oratio obliqua, which some writers find far from easy.

The understanding of a report can be greatly helped by consistent use of the different classes of headings available for division into sections and subsections; conversely, if headings are used indiscriminately, understanding is hindered. Again, punctuation used on any consistent plan will assist comprehension; stops thrown in at random are worse than useless.

It would seem that definite instruction, which need not occupy many hours of school time, is needed in certain subjects-such as punctuation and systematic division into sections and subsections; but that most of the troubles would pass away if the boys received plenty of practice under conditions favourable to the cultivation of a taste for writing. Essaywriting seems to be accepted as the standard method of gaining experience in the arrangement of words, but only a certain type of essay will aid report. writing - namely, that dealing with some subject which the writer has never before seen or heard described in words. A commentary upon a stageplay or film may be a better choice than a discussion of matters described in printed books. The reading of books by great authors is advocated by many. Clearly such reading is worth while for its own sake, but it is doubtful how far literary masterpieces can help the writing of scientific reports ; it is scarcely a compliment to their authors to suggest that a style skilfully developed for one purpose should be adopted for another. Nevertheless, the reading of certain authors may serve to enlarge the reader's vocabulary and may show him how the skilful selection of words can introduce delicate shades of meaning into the picture presented. Perhaps others may be found to provide examples of terseness-a matter of practical importance in days when the supply of paper is short and the patience of readers not inexhaustible.

Mr. Crammer, in opening the discussion, pointed out the psychological and sociological difficulties encountered by the grammar schools in the teaching of written expression in English. The grammar schools have in recent years admitted more and more pupils coming from homes in which there is little or no culture or encouragement in the reading of good books or conversation, let alone in writing. The social atmosphere generally has tended to counteract the training in writing given in the schools, a point which was taken up and emphasized by subsequent 
speakers, who laid stress on the decline in reading due to the cinema and the radio, as well as on the absence of æsthetic and literary standards in the home.

Others blamed the too early and the excessive specialization in the schools, a fault which the latter referred back to the universities and the increasingly high standard of attainment required by them for the award of scholarships. The 'objective' tests, consisting of one-word answers often used in the examinations for entrance to the grammar schools, were also criticized as not encouraging the teaching and practice of continuous written English in primary schools.

The vital importance of frequent practice in writing was admitted, but the burden of marking it imposed upon the teachers of English would be intolerably heavy if more practice was to be given without an increase in free periods for marking. The position would be better if all teachers, and not only those directly responsible for the teaching of English, regarded themselves as teachers of English as well as of their special subjects, and took the trouble to correct faulty English in all written work. One speaker rightly objected to the division of English into 'Science' English and 'Literary' English; the science graduate's difficulty in written expression is part of the general problem of the teaching of English to all pupils, irrespective of the forms of their later specializations.

After Dr. Evans had replied to the various points raised, Mr. Crammer summed up the discussion. It was clear, he said, (1) that there was general agreement about the necessity of all teachers, and not only the teachers of English, making the writing of English their concern, and (2) that continuous practice in writing is essential and must go on into and throughout the university course as well as throughout sehool life. It was worth considering whether in science scholarship examinations an essay and a general paper should be made compulsory and should be given considerable weight in deciding the awards. A committee representative of both schools and colleges was formed to investigate the problem further with a view to the formulation of constructive suggestions.

\section{PHYSIOLOGY AND BIOCHEMISTRY OF FATS AND LIPOIDS}

A PHYSIOLOGICAL symposium on fats, arranged by Le Centre National de la Recherche Scientifique and supported by the Rockefeller Foundation, was held in Paris during January 5-12. The meetings took place in the Department of General Physiology (Prof. G. Schaeffer) at the Sorbonne. Prof. E. F. Terroine presided.

The conference was opened with a paper by Prof. A. C. Frazer (Great Britain), who described new methods for the study of fat absorption problems, and presented the results of his investigations on the nature of the intestinal emulsifying system and hydrolysis of triglyceride. Prof. P. Desnuelles (France) reported experiments which have confirmed and extended Prof. Frazer's work on the formation of di- and mono-glycerides as endproducts of pancreatic lipolysis. Miss E. Le Breton (France) spoke of her demonstration of $\mathrm{A}$ - and B-lecithinases and cholesterol esterase in the pan- creatic juice. Its possible importance in the fat absorption mechanism was discussed. Prof. F. Verzar (Switzerland) reviewed his work on fat absorption, dealing particularly with his experiments relating the adrenal cortex to fat absorption. Prof. A. C. Frazer followed with a detailed account of the experimental work of his school on the intracellular and distributive phases of fat absorption. Prof. P. E. Verkade (Holland) gave a short paper which illustrated the inadequacy of the alleged solvent action of bile salt solutions for fatty acids. In the subsequent discussion, agreement was reached on the questions of intraluminar emulsification, the probable importance of hydrolysis, phosphorylation and the adrenal cortex in the fat absorption mechanism, and the possible occurrence of particulate absorption of fat. The extent of hydrolysis, amount of material absorbed in particulate form, the function of phosphorylation, and the nature of the influence of the adrenal gland on the fat absorption mechanism, were fully discussed.

Prof. T. Cahn (France) described investigations in dogs designed to determine the effect of muscular exercise, fasting, hyperthermia and panereatectomy on fat mobilization; and Dr. G. Clément (France) discussed the effects of unilateral denervation on fat mobilization in rats. The relationship between B-lecithinase and cholesterol esterase in the blood, and its influence in the formation of cholesterol esters, was raised by Miss E. Le Breton. Prof. M. Machebœuf (France) described his work on lipoprotein complexes in blood and gave an account of his extensive in. vestigations into the lipoid content of fractionated plasma proteins, and interesting observations on the replacement of lipoids in lipoprotein by substances of similar molecular structure. Prof. E. Chargaff (United States) gave a survey of the association between lipoids and proteins in biological systems, discussing the possible nature of the forces concerned in the construction of these complexes, with numerous illustrations from his own experiments.

Prof. A. C. Frazer presented an account of some new methods which had been developed for the studv of particulate fat in a protein environment. He described his experiments on blood fat and artificial particulate systems. He also reported X-ray diffraction studies on nerve lipoprotein which demonstrated the importance of water in lipoprotein structure, and other useful data. A lengthy discussion on all aspects of blood fat and the methods of study of lipoprotein complexes ensued. Later, Prof. E. Chargaff spoke of his work on blood coagulation, with particular reference to the part played by lipoproteins in these reactions.

Prof. K. Bernhard (Switzerland) described the biological degradation of fatty acids. With extensive references to his own work in this field, he discussed $\beta-, \omega-$ and multiple-oxidation. $H_{e}$ suggested that $\beta$-oxidation is most likely to occur under natural conditions and that ketones are mainly formed by condensation of the 2-carbon fragments split off by $\beta$-oxidation. Prof. P. Verkade discussed the relationship between the ingestion of carbohydrate and triundecylin and the excretion of undecanedioic acid in the urine in healthy human subjects. Administra. tion of carbohydrate causes an increase of dioic aciduria. The possible significance of liver glycogen in these experiments was discussed. Prof. R. H. Barnes (United States) gave a detailed account of recent work on ketogenesis. He described the various steps in the elucidation of this problem by the use of isotope-labelled materials, and put forward a new 